\title{
E-öğrenme Ortamlarında Öğrenme Stilleri ve Akademik Başarı Arasındaki İlişkinin İncelenmesi
}

\section{Investigation of the Relations between E-Learning Style and Academic Achievement in E-learning Environment}

\author{
Fatma Betül KURNAZ ${ }^{* *}$
}

\author{
Esin ERGÜN ${ }^{* * *}$
}

\begin{abstract}
Received: 16 March 2018
Research Article

Accepted: 13 February 2019

ABSTRACT: In this study, the effects of students learning styles on academic achievement was investigated in elearning environments and the answer for the question "are e-learning style, participation in online course and watching the lecture videos offline predictors of academic achievement?" is tried to examined. E-Learning Style Scale (Gülbahar and Alper, 2014) and Achievement Test were applied 501 (350 female and 151 male) students who received pedagogical formation education in e-learning environment during the 2016-2017 academic year. The research was carried out online with learning management systems in the measurement and assessment course for 14 weeks. The certificate of pedagogical formation was given to students at the end of the course. The Achievement Test developed by researchers. This test was tested in another group similar to the study group and found reliable and valid results. The scores obtained from this test were accepted as a measure of academic achievement. Data were analyzed by stepwise multiple regression analyses. According to the results, participation in online course, watching video recordings, active learning style and independent learning style were found as predictors of students' academic achievement. These four variables account for $7 \%$ of the total variance in academic achievement.
\end{abstract}

Keywords: E-learning, learning styles, academic achievement.

ÖZ: $\mathrm{Bu}$ çalışmada e-öğrenme ortamlarındaki öğrencilerin öğrenme stillerinin akademik başarı üzerindeki etkisi araştırılmış ve "e-öğrenme stilleri, çevrimiçi derslere katılım, video kayıtlarını izleme değişkenleri akademik başarının yordayıcısı mıdır?” sorusuna yanıt aranmıştır. Araştırmada 2016-2017 öğretim yılında bir e-öğrenme ortamında pedagojik formasyon eğitimi alan 501 öğrenciye (351 kadın, 150 erkek) E-Öğrenme Stilleri Ölçeği (Gülbahar ve Alper, 2014) ve Başarı Testi uygulanmıştır. Araştırma ölçme ve değerlendirme dersi kapsamında öğretim yönetim sistemi üzerinden 14 hafta boyunca çevrimiçi derslerle yürütülmüştür. Öğrencilere bu kurs sonunda pedagojik formasyon eğitimi sertikası verilmiştir. Başarı Testi araştırmacılar tarafından geliştirilmiştir. Bu test araştırma grubuna benzeyen başka bir grupta denenerek güvenilir ve geçerli sonuçlar verdiği belirlenmiştir. Bu testten alınan puanlar akademik başarının ölçüsü olarak kabul edilmiştir. Verilerin çözümlenmesinde aşamalı çoklu regresyon analizi kullanılmıştır. Araştırma sonuçlarına göre, çevrimiçi derslere katılma, video kayıtlarını izleme, aktif öğrenme stili ve bağımsız öğrenme stili e-öğrenme ortamında akademik başarıyı yordamaktadır. Bu dört değişken akademik başarıdaki toplam varyansın \%7'sini açıklamaktadır.

Anahtar kelimeler: E-öğrenme, öğrenme stilleri, akademik başarı.

** Corresponding Author: Dr., Karabuk University, Karabuk, Turkey, betulkurnaz@karabuk.edu.tr, https://orcid.org/0000-0002-7042-2159

***** Dr., Karabuk University, Karabuk, Turkey, esinergun@karabuk.edu.tr, https://orcid.org/0000-0002-1443-514X

\section{Citation Information}

Kurnaz, F. B., \& Ergün, E. (2019). E-öğrenme ortamlarında öğrenme stilleri ve akademik başarı arasındaki ilişkinin incelenmesi. Kuramsal Ĕgitimbilim Dergisi [Journal of Theoretical Educational Science], 12(2), 532-549. 


\section{Giriş}

Bilgi ve iletişim teknolojilerinde meydana gelen gelişmeler, öğrenenlere sağlamış olduğu olanaklar sayesinde çevrimiçi öğrenmenin okul eğitiminde ve yaşam boyu öğrenmedeki önemini artırmış görünmektedir. Öğrenme-öğretme sürecinde öğretmenin rolü bilgi aktarmaktan öğrenciye rehber ya da danışman olmaya evrilmiştir (Yurdakul, 2016). Öğretmenin rehber olduğu öğrenme ortamları, öğrenenlerden bilgiyi inşa etmelerinin, öğrenmeyi öğrenmelerinin beklenmesine neden olmuştur. $\mathrm{Bu}$ durum öğretim ortamlarında öğrenen özelliklerinin önemini artırmıştır (Nitko, 1996).

Çok sayıda araştırmada örgün öğretim durumlarında öğrenme stillerinin akademik başarıyla ilişkisi araştırılmış ve çoğunda öğrenme stillerinin akademik başarıyı etkilemediği sonucuna varılmıştır (Pashler, McDaniel, Rohrer, \& Bjork, 2008; Willingham, Hughes, \& Dobolyi, 2015). Her ne kadar öğrenme stillerinin öğrenme sürecinde etkili olmadığına ilişkin araştırma sonuçları olsa da alanyazında öğrenme ortamlarının öğrenme stillerine göre düzenlenmesinin önerildiğine ilişkin çalışmalar da (Chen, 2019; Li, Yin, Zhang, \& David, 2019) söz konusudur. Ayrıca e-öğrenme ortamlarında e-öğrenme stilleri ile akademik başarı arasındaki ilişkilerin araştırıldığı az sayıda araştırma olması, e-öğrenme ortamlarında e-öğrenme stillerinin akademik başarı üzerindeki etkisinin örgün öğrenme ortamlarındakine göre farklılık gösterip göstermediğini belirleme açısından önemli olabilir. Kia, Aliapour ve Ghaderi (2009) çalışmalarında e-öğrenme ortamlarında tek başına, sosyal, işitsel ve sözel öğrenme stillerine sahip öğrencilerin daha başarılı olduğunu bulmuştur. Benzer çalışmalarla içerik ya da bilgi yönetim sistemi değiştiğinde öğrenme stillerinin öğrenci başarısıyla ilişkisinin araştırılması konuya farklı bir yaklaşım kazandırabilir. $\mathrm{Bu}$ nedenle bu araştırma, e-öğrenme ortamlarında e-öğrenme stilleri ile akademik başarı arasındaki ilişkileri araştırmayı amaçlamıştır.

Öğrencinin yeni bir bilgiyi öğrenmesi veya hatırlaması için kullandığı yol öğrenme stili olarak adlandırılır. Felder ve Silverman (1988), öğrenme stilini "bireylerin bilgiyi alma, tutma ve işleme sürecindeki karakteristik güçlülüğü ve tercihleri” olarak tanımlamaktadır. Her öğrenci farklı bir yolla öğrenmeyi tercih eder. Bazı öğrenciler ders çalışırken ya da öğrenirken yazılı materyalleri kullanmak ister ve yazılı açıklamaların kendileri için daha etkili olduğunu kabul eder; bazıları ise görsel materyalle öğrenmeyi tercih eder (Felder, 1996). Öğrenme stili bireyin ne öğrendiğiyle değil, nası1 öğrendiğiyle ilgilidir. Öğrenme stillerine ilişkin farklı yaklaşımlar vardır: Kolb Öğrenme Stili Modeli (Kolb, 1981), Dunn ve Dunn Öğrenme Stili Modeli (Rita \& Dunn, 1993), Gregorc Öğrenme Stili Modeli (Gregorc, 1979), Butler Öğrenme Stili Modeli (Butler, 1987), McCarthy (4 MAT) Öğrenme Stili Modeli (McCharthy, 1987), Canfield Öğrenme Stili Modeli (Canfield, 1988), Silver-Hanson Öğrenme Stili Modeli (Silver, Hanson, \& Strong, 1979), Witkin Öğrenme Stilleri (Witkin, 1964). Bu modeller arasında bilişsel, duyuşsal ve devinimsel davranışsal özelliklerin tümünün birlikte değerlendirildiği modeller bulunmaktayken; sadece bilişsel ya da psikolojik değişkenlere ilişkin tek bir boyutun dikkate alındığı modeller de vardır (De Bello, 1990, akt, Yavuzalp \& Gürol, 2017).

Öğrenme stilleri ile kullanılan öğretim stratejilerinin uyumlu olmasıyla öğrenciler öğrenmede daha iyi performans göstermektedir; Bu nedenle öğretmenlerin farklı öğretim yöntemlerini bir arada kullanmaları farklı öğrenme stillerine sahip olan 
öğrencilerin benzer performans göstermelerini kolaylaştırabilir (Felder, 1993). Öğrenme stillerinin cinsiyete dayalı bir farklılık içerdiğine; erkek öğrencilerin dokunarak öğrenmeyi kız öğrencilere göre daha fazla tercih ettiklerine ve görsel öğrenme stiline sahip olduklarına; kız öğrencilerin ise işitme yoluyla öğrenmeyi daha fazla tercih ettiğine ilişkin araştırmalar da söz konusudur (Geiser, Dunn, Deckinger, Denig, Sklar, Beasley, \& Nelson, 2000). Cassidy (2004) bağlamdan bağımsız öğrenme eğiliminde olan öğrencilerin, içsel güdülenmelerinin daha fazla olduğunu, bağlama dayalı öğrenmeyi tercih eden öğrencilerin ise dişsal güdülenmelerinin daha fazla olduğunu söylemektedir. Kendi kendine öğrenme becerileri ve kendi kendine öğrenmenin çıtıları bireyin öğrenmede tercih ettiği yollardan etkilenebilir. Bu nedenle akademik başarının, sınıf içi performansın ya da öğrenme düzeyinin öğrenme stillerinden ne düzeyde etkilendiği önemli görülebilir. Ayrıca öğrenme stillerinin sözü edilen değişkenlerle ilişkisi, hem örgün yollarla gerçekleştirilen eğitim ortamlarında hem de uzaktan eğitim yoluyla gerçekleştirilen eğitim ortamlarında etkili olabilir. Bu araştırmada uzaktan eğitim yoluyla gerçekleştirilen bir öğretim yönetim sistemi kullanıldığından e-öğrenme stilleri araştırmanın odak noktasını oluşturmuştur. Teknoloji yoğunluklu ortamlarda öğrenme stilleri çevrimiçi öğrenme stili olarak adlandırılmaktadır (Dă̆ \& Geçer, 2009).

E-öğrenme stillerinin öğrencilerin sınıf içindeki performanslarını hangi düzeyde açıklayabildiği sorusu öğretim ortamlarının düzenlenmesinde ya da öğrenci niteliklerinin beklenen yönde değişimini sağlamada önemli olabilir. Öğrenme stillerinin örgün öğretimde öğrenci başarısını etkilemediğine ilişkin çalışmalar söz konusu olsa da, elektronik öğrenme ortamlarda olabileceğine ilişkin varsayımlar alanyazında belirtilmektedir (Chen, 2019; Kia, Aliapour, \& Ghaderi, 2009; Li, Yin, Zhang, \& David, 2019). Bu varsayımların test edilmesi öğrencilerin elektronik öğrenme sürecindeki performansını ya da akademik başarısını açıklayabilecek değişkenlerin belirlenmesi konusuna da 1şık tutabilir.

Geleneksel öğrenme ortamlarında ve çevrimiçi öğrenme ortamlarında çevresel düzenlemelerin, çevresel uyaranların, öğretmen ve öğrenci rollerinin farklılaşması öğrencilerin öğrenme yollarında da farklara yol açabilir (Badge, Saunders, \& Cann, 2012; Maki \& Maki, 2007). Beadles II ve Lowery (2007), e-öğrenme ortamını tercih eden öğrenciler ile geleneksel öğrenme ortamını tercih eden bireylerin öğrenme stillerinin farklı olduğundan söz etmektedirler. Bu tercih farklılığının birden fazla nedeni olabilir. Örneğin e-öğrenme ortamlarında öğrencilerden gerekli donanımı ve yazılımı kullanmaları ve teknolojiyi kullanmada az da olsa yetkin olmaları beklenir. Ayrica yazarak iletişim kurma, içsel güdülenmeye sahip olma ve öz denetim, ders çalışmada yeterli zamanı ayırma gibi değişkenler de öğrencilerin öğrenmeyi tercih ettiği yolları etkileyebilir (Howland \& Moore, 2002).

Araştırmalar, e-öğrenme ortamlarında öğrencilerin bireysel farklılıklarına ve öğrenme özelliklerine dikkat ederek sınıf içi etkinlikleri düzenlemenin, öğrenmenin kalitesini ve öğrencilerin akademik başarılarını artırmada önemli bir rol oynadığını ortaya koymuştur (Jahanbakhsh, 2012; Omar, Mohamad, \& Paimin, 2015; Veznedaroğlu \& Özgür, 2005). Tulbure (2011), öğrencilerin öğrenme stillerine göre hazırlanmış bir öğretimin akademik başarıyı arttırdığını ve öğrencilerin öğrenme sonuçlarını, derse karş1 tutumlarını, öğrenmeye ilişkin güdülenmelerine katk1 sağladığını belirtmektedir. 
E-öğrenme ortamlarının birçok kurumda hızla yaygınlaşmasıyla birlikte, bu ortamlarda öğrenen özelliklerinin araştırılması, e-öğrenme ortamlarının daha etkili tasarlanması ve öğrenen performansının artırılması büyük önem taşımaktadır. Özellikle bireysel farklılıkların öğrenmede etkisi sıkça dile getirilirken, Buerck, Malstrom ve Peppers (2003) uzaktan eğitimde öğrenci başarısını açıklamaya çalışan çalışmalarda öğrenme stillerinin bir değişken olarak incelenmemesinin bir eksiklik olacağını dile getirmiştir. Cook (1991) ise öğrenme stillerinin belirlenmesinin, öğrenme stil farkındalığının kazandırılmasında önemli olduğunu ve öğrenme stili farkındalığının kazandırılmasının akademik başarı üzerinde olumlu bir katkısının olduğunu belirtmektedir.

Özetle, Türkiye'de yapılmış çalışmalar incelenmiş, e-öğrenme ortamlarında akademik başarının öğrenme stilleriyle olan ilişkisinin incelendiği az sayıda çalışma olduğu belirlenmiştir. Ayrıca bu çalışma planlanırken bir öğrencinin sahip olduğu eöğrenme stillerinin tek başına başarıyı açıklamada yeterli olmayabileceği düşünülmüştür. Örneğin derslere sıklıkla devam eden bir öğrenci ile derslere her zaman devam eden bir öğrencinin öğrenme stilleri aynı olsa da akademik başarıları arasında fark oluşabilecektir. Bu nedenle öğrencilerden derslere düzenli katılımlarına ilişkin bilgilerin toplanmasının da uygun olacağı kararına varılmıştır. Bu amaçla öğrencilerden derslere katılımları ve ders kayıtlarını izleme durumlarına ilişkin bilgiler de toplanmıştır.

$\mathrm{Bu}$ çalışmada e-öğrenme ortamlarındaki öğrencilerin öğrenme stillerinin akademik başarı üzerindeki etkisi araştırılmıştır. Araştırmada "e-öğrenme stilleri, çevrimiçi derslere katılım, video kayıtlarını izleme değişkenleri akademik başarının yordayıcısı mıdır?" sorusuna yanıt aranmıştır.

\section{Yöntem}

Bu bölümde araştırmanın modeli, çalışma grubu, veri toplama araçları, verilerin toplanması ve verilerin çözümlenmesi aşamalarına yer verilmiştir.

\section{Araştırma Modeli}

$\mathrm{Bu}$ araştırma öğrencilerin akademik başarıları ile öğrenme stilleri, çevrimiçi derslere katılımları ve senkron derslerin video kayıtlarını izleme değişkenleri arasındaki ilişkileri ve bu değişkenlerin öğrencilerin akademik başarısını hangi düzeyde yordadığını belirlemeyi amaçlayan yordayıcı ilişkisel bir çalışmadır. İlişkisel araştırmalarda, iki ya da daha fazla değişken arasındaki ilişkiler bir müdahalede bulunulmaksızın incelenir (Büyüköztürk, Kılıç-Çakmak, Akgün, Karadeniz, \& Demirel, 2009).

\section{Çalışma Grubu}

Çalışma grubunu oluşturan öğrenciler, 2016-2017 öğretim yılında 14 hafta boyunca ölçme ve değerlendirme dersini Pedagojik Formasyon Sertifika Programı kapsamında uzaktan eğitim yoluyla almıştır. 2016-2017 öğretim yılında uzaktan eğitim yoluyla formasyon alan öğrenci sayıs1 900'dür. Bu öğrencilerden araştırmaya katılmaya gönüllü olan 672 öğrenciye formlar uygulanmıştır. Ancak formlarda bir yüzü doldurulmuş arka yüzü doldurulmamış, önemli ölçüde eksik bilgi içeren formlar araştırma dışında bırakılmıştır. Böylece 2016-2017 öğretim yılında pedagojik 
formasyon eğitimi alan 501 öğrenciden elde edilen veriler çözümlenmiştir. Çalışma grubunu oluşturan öğrenciler farklı lisans alanlarında son sınıf öğrencisiyken Pedagojik Formasyon Sertifika Programı'na katılmışlardır. Araştırma kapsamında örneklem grubuna dâhil edilen öğrenci özellikleri Tablo 1'de verilmiştir.

Tablo 1

Çalışma Grubunun Özellikleri

\begin{tabular}{llcc}
\hline & Nitelik & $f$ & $\%$ \\
\hline \multirow{2}{*}{ Cinsiyet } & Kadın & 351 & 70.1 \\
& Erkek & 150 & 29.9 \\
\hline İlahiyat & 89 & 17.8 \\
& Tarih & 79 & 15.8 \\
& İngiliz dili ve edebiyatı & 63 & 12.6 \\
Türk dili ve edebiyatı & 62 & 12.4 \\
Çocuk gelişimi ve eğitimi & 54 & 10.8 \\
Coğrafya & 31 & 6.2 \\
Sosyoloji & 24 & 4.8 \\
Matematik & 23 & 4.6 \\
Oisărenim Gördüğü Alanı & Spor Yöneticiliği & 19 & 3.8 \\
& Sanat Tarihi & 15 & 3.0 \\
& Hemşirelik & 11 & 2.2 \\
Ebelik & 11 & 2.2 \\
Resim & 6 & 1.2 \\
Arkeoloji & 7 & 1.4 \\
Fizik tedavi ve rehabilitasyon & 3 & 0.6 \\
Müzik & 3 & 0.6 \\
Kimya & 1 & 0.2 \\
\hline
\end{tabular}

\section{Veri Toplama Araçları}

Araştırmada akademik başarının bir ölçüsü olarak Başarı Testi’nden alınan puanlar kullanılmıştır. Ayrıca araştırmada E-Öğrenme Stilleri Ölçeği ve Kişisel Bilgi Formu kullanılmıştır.

Kişisel bilgi formu. $\mathrm{Bu}$ formda, öğrencinin lisansta öğrenim gördüğü alan, çevrimiçi derslere katılım durumu ve çevrimiçi derslerin video kayıtlarını izleme durumuna ilişkin sorular yer almaktadır.

E-Öğrenme stilleri ölçeği. Gülbahar ve Alper (2014) tarafından uzaktan eğitim programına kayıtlı 2344 öğrenciden elde edilen verilerle geçerlilik ve güvenilirlik çalışmaları yapılarak geliştirilmiştir. Yedi alt faktör ve 38 maddeden oluşmaktadır. Bağımsız öğrenme, sosyal öğrenme, görsel-işitsel öğrenme, aktif öğrenme, sözel 
öğrenme, mantıksal öğrenme ve sezgisel öğrenme ölçeğin alt faktörlerini oluşturmaktadır. Bağımsız öğrenme, kendi başına çalışmayı tercih etme; biraz rehberlikle kendi öğrenmelerinin sorumluluğunu üstlenme; bireysel hazırlıklarını tamamladıktan sonra grup çalışmasına katılma vb. davranışları daha çok tercih eden bireylerin öğrenme stilini tanımlamaktadır. Sosyal öğrenme, etkileşimli grup etkinliklerine katılmayı sevme; çalışmalar sırasında etkileşime önem verme; sohbet, sanal sınıf ya da beyaz tahta uygulamaları gibi eş zamanlı etkinliklere katılma vb. davranışları gösteren bireylerin öğrenme stilidir. Görsel-işitsel öğrenme, en iyi görerekişiterek öğrendiğini düşünme; resim, tablo, grafik vb. ögelerle öğrenmeyi tercih etme; dinleyerek öğrenmekten zevk alma vb. davranışları gösteren bireylerin öğrenme stilidir. Aktif öğrenme, en iyi yaparak öğrendiğini düşünme; keşfetmekten ya da araştırmaktan zevk alma; yaratıcılık gerektiren sorunları çözmekten keyif alma vb. davranışları gösteren bireylerin öğrenme stilidir. Sözel öğrenme, edebiyat, tarih, dil gibi konularda çalışma yürütmekten zevk alma; bir konuda tartışma yürütmekten zevk alma; en iyi okuyarak öğrendiğini düşünme vb. davranışları içeren öğrenme stilidir. Mantıksal öğrenme, hesaplama gerektiren etkinlikleri sevme; bir plan dâhilinde çalışma; sorunları analitik süreçlerle çözme vb. davranışları içeren öğrenme stilidir. Sezgisel öğrenme, öğrenme nesnesini duygularıyla ilişkilendirme; tümdengelimsel bir öğrenme süreci takip etme; sorun çözerken hiyerarşik yollardan çok rastlantısal yolları deneme vb. davranışları kapsayan öğrenme stilidir.

Ölçeğin geliştirilmesi aşamasında Gülbahar ve Alper (2014), 56 maddelik bir madde havuzu oluşturmuş, taslak ölçeği 2344 öğrenciden elde ettikleri verilerle Açımlayıcı Faktör Analizi (AFA) ile çözümlemiştir. AFA sonucunda, 38 maddeden oluşan yapının yedi faktör olduğu ve faktör yük değerlerinin .46 ile .82 arasında değiştiği belirtilmiştir. AFA'dan sonra Doğrulayıcı Faktör Analizi (DFA) uygulanmış ve DFA sonucunda modelin iyi uyum gösterdiği sonucuna ulaşılmıştır. Ölçeğin faktörlerinin iç tutarlılık katsayısı .72 ile .82 arasında değişmektedir. Elde edilen bu bulgular E-Öğrenme Stilleri Ölçeğinin güvenilir ve geçerli sonuçlar üretebildiğini düşündürmektedir.

Başarı testi. $\mathrm{Bu}$ çalışmada uzaktan eğitim derslerinin içeriğine yönelik alanyazın taranmış (Özçelik, 2010; Turgut \& Baykul, 2012), tüm konu ve kapsamı örnekleyebilecek 50 soruluk bir madde havuzu oluşturulmuştur. Oluşturulan taslak maddeler örneklem grubuna benzeyen 275 öğrenciye uygulanarak madde analizleri yapılmıştır. Madde analizleri sonucunda, aynı kazanımla ilgili sorular arasından ayırt ediciliği en yüksek ve orta güçlüğe yakın olan sorular seçilmiştir. Böylece 25 soruluk formun nihai olarak uygulanmasına karar verilmiştir. Nihai formda yer alan maddelerin ayırt edicilik indeksleri .36 ile .57 ve maddelerin güçlük indeksleri .36 ile .75 arasında değişmektedir. Testin ortalama güçlüğü .56'dır ve testin KR-20 güvenilirliği .81 olarak hesaplanmıştır. Elde edilen bu sonuçlar Başarı Testi'nin güvenilir ve geçerli sonuçlar verebileceğini düşündürmektedir.

\section{Verilerin Toplanması ve Çözümlenmesi}

Ölçme ve Değerlendirme dersi Moodle üzerinden 14 hafta boyunca çevrimiçi derslerle gerçekleştirilmiştir. Dersler Moodle üzerinden Adobe Connect alt yapıs1 kullanılarak kaydedilmiştir. Bu durum öğrencilerin dersleri tekrar dinlemelerine olanak 
sağlamıştır. Dijital gereçlerin kullanıldığı derslerde öğrencilerin derse katılımı yalnızca sohbet penceresi kullanılarak sağlanmıştır. Öğrencilerin ekran görüntülerini paylaşmalarına, mikrofon ve kamera kullanmalarına izin verilmemiştir. Yönetici görüntülü kamerayı kullanmamış, dersleri video konferans biçiminde yürütmüştür. EÖğrenme Stilleri Ölçeği ve Kişisel Bilgi Formu öğrenciler ara sınava geldikleri gün sınavdan sonra uygulanmıştır. Başarı Testi ise yarıyıl sonu sınavı olarak öğrencilere uygulanmıştır. Başarı Testinin öğrencilerin geçme notunu belirleyecek olan sınavda kullanılması öğrencilerin en yüksek performansı göstermelerine olanak sağlamış olabilir. Bu durumun yanıtlayıcıların yanıtlamaya isteksiz olmalarından kaynaklanan sorunları en aza indireceği varsayılmıştır.

Verilerin çözümlenmesinde aşamalı çoklu regresyon analizi kullanılmıştır. Çoklu doğrusal regresyon analizinin varsayımlarından olan normal dağılım, doğrusallık, sabit varyans, otokorelasyonun olmaması, bağımsız değişkenler arasında çoklu bağlantının olmaması durumları incelenmiştir. Tolerans değerinin 0.20'den büyük, VIF değerinin 10'dan küçük, CI değerinin 30'dan küçük çıkması çoklu bağlantı sorununun bulunmadığını göstermektedir (Büyüköztürk, 2017). Durbin-Watson değerinin 1.5 ile 2.5 arasında olması beklenen bir durumdur (Albayrak, 2006; Kalaycı, 2009). Elde edilen sonuçların sözü edilen ölçütlerle karşılaştırılması amacıyla uygun çözümlemeler yapılmıştır. Şekil 1 ve Şekil 2'de elde edilen verilerin çoklu doğrusal regresyon analizinin normallik ve doğrusallık varsayımlarına ilişkin sonuçlar verilmiştir.

Şekil 1. Standardize Edilmiş Yordanan Değerler İçin Oluşturulan Histogram ve Normal Dağılım Eğrisi

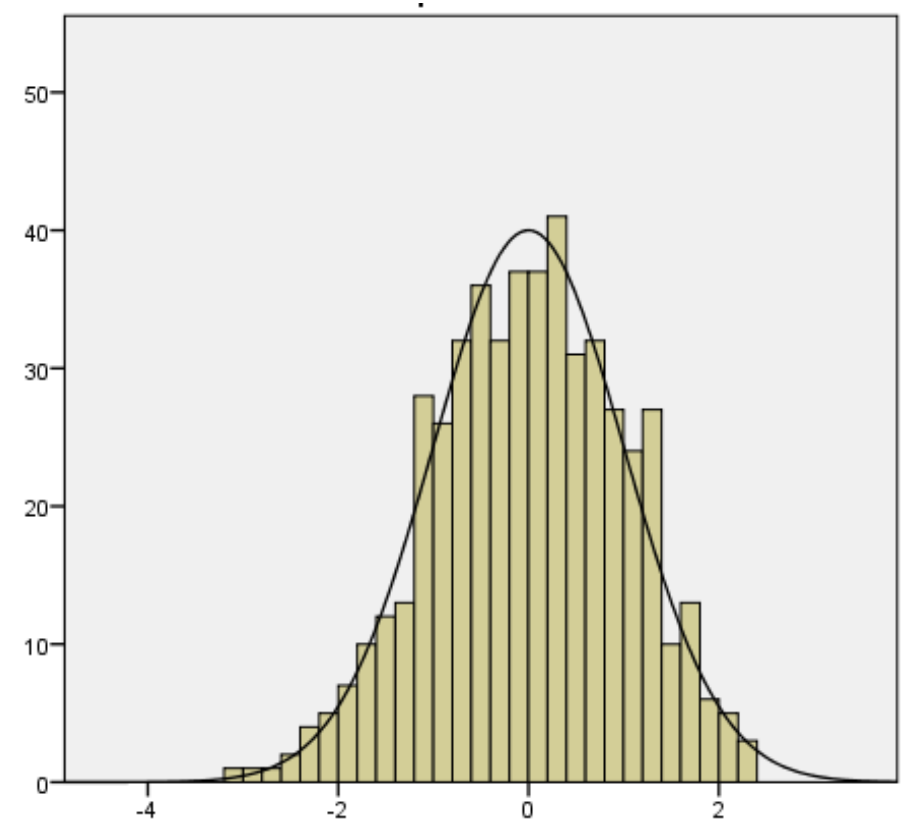


Şekil 2. Standardize Edilmiş Artık Değerler İle Standardize Edilmiş Yordanan Değerler İçin Oluşturulan Saçılma Diyagramı

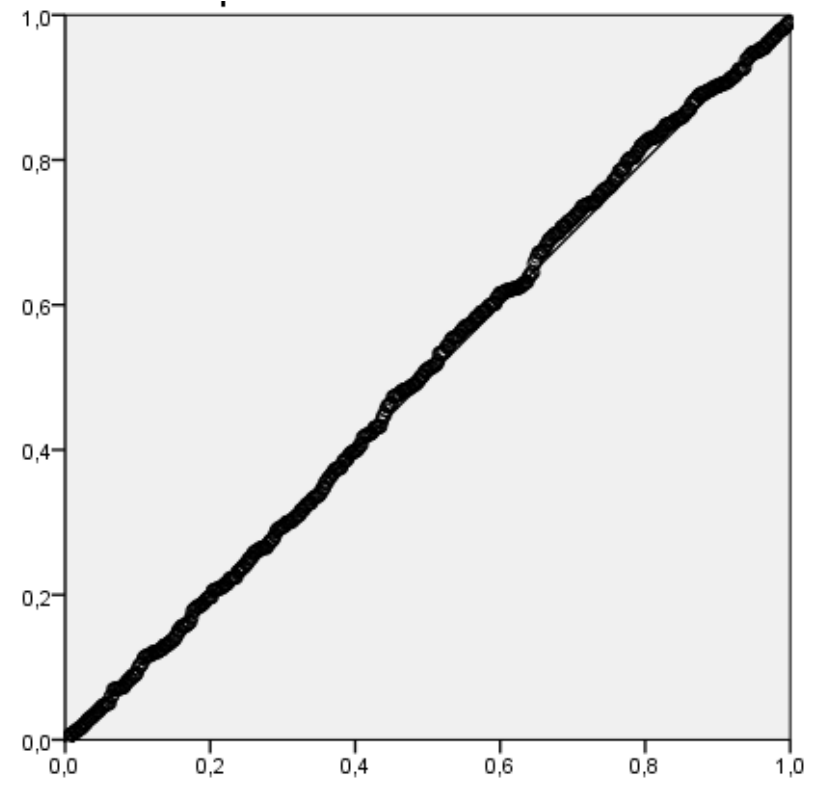

Şekil 1 ve 2 incelendiğinde, yordanan değerler için oluşturulan histogram ve normal dağılım eğrilerinin normal bir dağılım gösterdiği, saçılma diyagramında noktaların bir eksen etrafında toplanma eğiliminde olduğu, saçılma diyagramının doğrusal ve pozitif yönde bir ilişkiyi tanımladığı söylenebilir. Normallik ve doğrusallık varsayımlarının test edilmesinin ardından çoklu bağlantı sorunu olup olmadığ incelenmiştir. Tolerans değerlerinin 0.74 ile 0.89 arasında ve varyans büyüme faktörünün (VIF) 1.00 ile 1.48 arasında değiştiği, durum indeks (CI) değerinin 17.89 ve Durbin-Watson değerinin 1.60 olduğu belirlenmiştir. Bu istatistikler verilerin aşamalı çoklu regresyonun varsayımlarını karşıladığının bir kanıtıdır.

Bir değişkenin regresyon eşitliğine alınmasında $\alpha=0.05$ düzeyi kullanılmıştır. Regresyon eşitliğine alınan bir değişkenin sonraki aşamalarda analiz dışında bırakılabilmesi için $\alpha=0.10$ düzeyi kullanılmıştır. Araştırmanın yordanan değişkeni çevrimiçi öğrenme ortamlarında akademik başarı düzeyidir. Araştırmada yordayıcı değişkenler sürekli ve süreksiz değişkenlerden oluşmaktadır. E-Öğrenme Stilleri Ölçeğinin alt faktörleri olan bağımsız öğrenme, sosyal öğrenme, görsel-işitsel öğrenme, aktif öğrenme, sözel öğrenme, mantıksal öğrenme ve sezgisel öğrenme faktörleri faktör puanları elde edilerek analize dâhil edilmişlerdir. Süreksiz değişkenler (senkron derslere katılım durumu ve senkron dersleri kayıtlardan izleme) ise "dummy değişken" olarak kodlanarak analize dahil edilmişlerdir. Dummy değişken olarak kodlanan süreksiz değişkenlerin kodlama süreci aşağıda verilmiştir.

- Senkron derslere her zaman ya da çoğunlukla katılım durumu dummy değişken olarak atanmış ve "1" ile kodlanmış, senkron derslere neredeyse hiç katılmama ya da çok az katılma durumu ise " 0 " ile kodlanmıştır.

- Senkron dersleri video kayıtlardan izleme dummy değişken olarak atanmış ve "1" ile kodlanmış, senkron dersleri video kayıtlardan izlememiş olma ise "0" ile kodlanmıştır. Dummy değişkenler analize aynı sırayla dâhil edilmiştir. 


\section{Bulgular}

$\mathrm{Bu}$ bölümde e-öğrenme stilleri, senkron derslere katılım ve senkron dersleri video kayıtlarından izleme değişkenlerinin çevrimiçi öğrenme ortamlarına dayalı akademik başarı notlarını yordama gücüne ilişkin bulgulara yer verilmiştir.

Tablo 2

Akademik Başarı Notlarını Yordayan Değişkenlere İlişkin Aşamalı Çoklu Regresyon Analizi Sonuçları

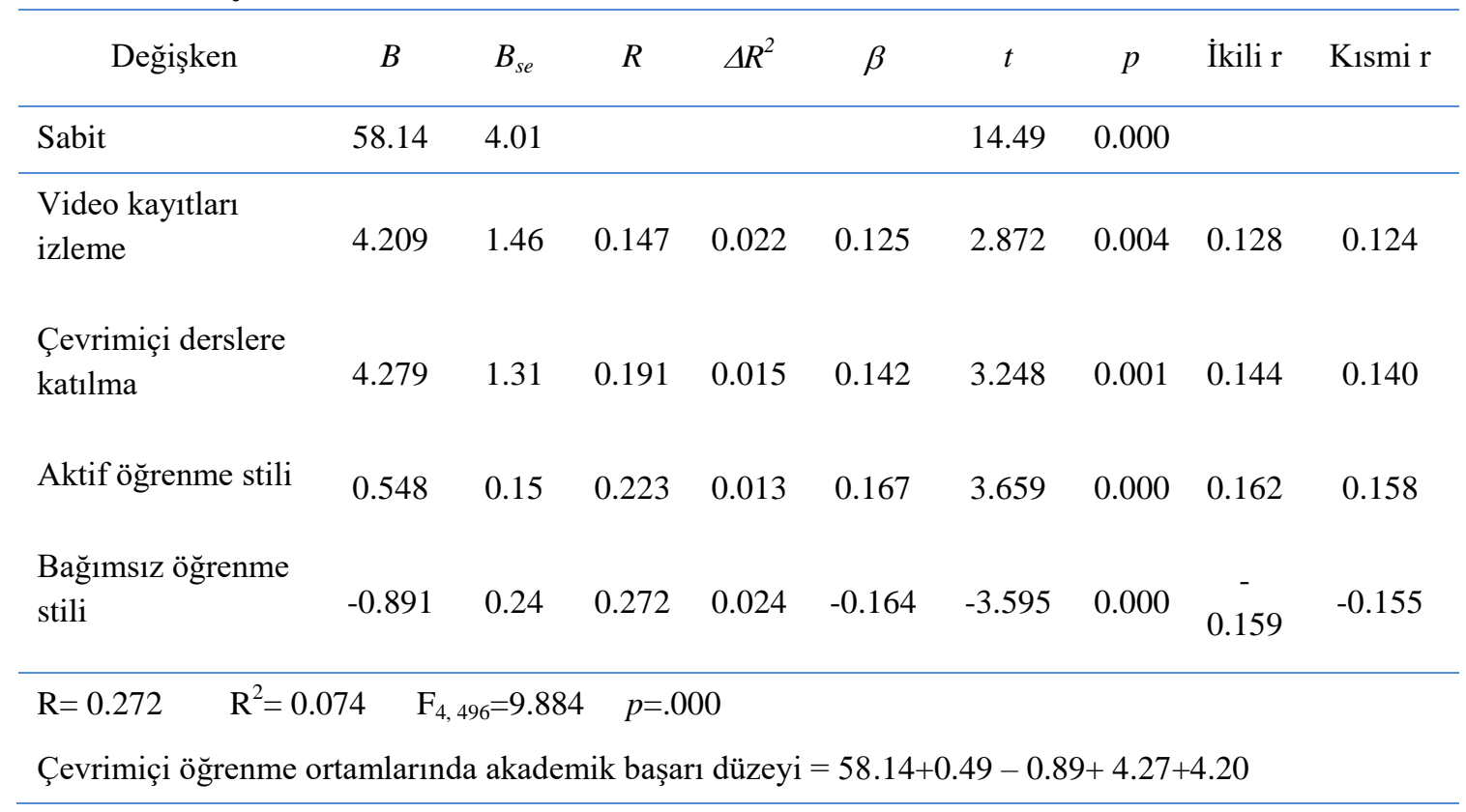

Video kayıtlarını izleme, çevrimiçi derslere katılım, aktif öğrenme ve bağımsız öğrenme stili akademik başarının yordayıcıları olarak regresyon eşitliğine girmiştir $\left(R=0.27 ; R^{2}=0.07 ; p<.01\right)$. Regresyon analizinde t-testi sonuçları incelendiğinde eşitliğe giren tüm değişkenlerin akademik başarının yordayıcıları olduğu sonucuna ulaşılmaktadır.

İkili ve kısmi korelasyonlar incelendiğinde, aktif öğrenme stili $(r=.16)$, çevrimiçi derslere katılma $(r=.14)$ ve video kayıtlarını izleme $(r=.13)$ ile akademik başarı arasında düşük ve pozitif yönlü bir ilişki bulunmaktadır. Bağımsız öğrenme stili ile akademik başarı arasında düşük düzeyde ve negatif bir ilişkinin ( $r=-.16)$ olduğu görülmektedir. Diğer değişkenler kontrol altına tutulduğunda ilişkilerin büyük ölçüde değişmediği, aynı kaldığı görülmektedir.

Standardize edilmiş regresyon katsayıları $(\beta)$, akademik başarıyı açıklamada yordayıcıların göreli önem sırasını göstermektedir. $\mathrm{Bu}$ durumda akademik başarıyı açıklayan yordayıcıların göreli önem sırası da aktif öğrenme stili, bağımsız öğrenme sitili, çevrimiçi derslere katılma ve video kayıtları izlemedir. Bağımsız ve aktif öğrenme stilleri çevrimiçi derslere katılma ve video kayıtlarını izleme değişkenlerine göre önem sırası bakımından daha ön plandadır.

Regresyon analizinde bağımsız, sosyal, görsel-işitsel, aktif, sözel, mantıksal ve sezgisel öğrenme faktörlerinden yalnız aktif öğrenme ve bağımsız öğrenme stili analize girmiştir. Yordayıcı değişkenlerin $\Delta R^{2}$ değerleri incelendiğinde, akademik başarıdaki toplam varyansı açıklamaları bakımından video kayıtlarını izleme \%2, çevrimiçi 
derslere katılma \%1, aktif öğrenme stili \%1 ve bağımsız öğrenme stili $\% 2$ oranında katkı sağlamaktadır. Bu dört değişken birlikte akademik başarı durumuna ilişkin toplam varyansın \%7'sini açıklamaktadır.

\section{Tartışma, Sonuç ve Öneriler}

Araştırma sonuçlarına göre, analize dâhil edilen dokuz değişkenden dördü akademik başarının yordanmasına katkı sağlamıştır. Video kayıtlarını izleme, çevrimiçi derslere katılma, aktif öğrenme stili ve bağımsız öğrenme stili e-öğrenme ortamında akademik başarıyı yordamaktadır.

Araştırma bulgularına göre, çevrimiçi derslere katılım ve derslerin video kayıtlarını sonraki bir zamanda izleme akademik başarıyı artırmaktadır. Derslerin yürütüldüğü zaman içinde derse katılım ya da derslere ait video kayıtlarını izleyen öğrencilerin akademik başarıları olumlu yönde etkilenmektedir. Bu durum öğrencilerin öğrenme yaşantıları sırasında öğretmenin rolünün önemini de göstermektedir. Öğretmenin öğrenmeyi kolaylaştıracak yaşantılar sağlaması önemli bir etkendir. Ancak, öğrencilerin derse katılımının yalnız öğretmenin çabası ile açıklanmasının tek yönlü bir bakış açısı sağlayacağı düşünülmektedir. Örneğin, öğrencilerin dersi takip etmeye ve öğrenmeye istekli olması ya da akademik yılmazlık düzeylerinin yüksek olması gibi etmenler öğrencilerin derse katılımlarının bir göstergesi olabilir. Şenel ve Kutlu (2015), Ankara Üniversitesi Uzaktan Eğitim Merkezi'nde öğrenim gören 302 öğrenci üzerinde yürüttüğü çalışmada eğitsel videoları izleyerek ve sanal derslere katılarak ders çalışan öğrencilerin akademik başarılarının yüksek olduğunu belirlemiştir. Savaş ve Arıcı (2009), video destekli öğretim nesnesinin animasyon destekli öğretim nesnesine göre akademik başarıyı olumlu yönde etkilediği sonucuna ulaşmıştır.

Aktif öğrenme stiline sahip olma durumu ile akademik başarı arasında pozitif ve düşük düzeyde bir ilişki olduğu, aynı zamanda aktif öğrenmenin akademik başarının bir yordayıcısı olduğu belirlenmiştir. Alanyazında e-öğrenme stillerinin akademik başarıyı olumlu yönde etkilediğine ilişkin çalışmalar (Hsu, 1994; Ross, Drysdale, \& Schulz, 2001) olduğu gibi öğrenme stillleri ile akademik başarı arasında ilişki olmadığına yönelik bulgular da (Omar ve diğerleri, 2015; Rovai \& Grooms, 2004) söz konusudur. Öğrenme stil modeline dayalı ders tasarımlarının akademik başarı üzerinde olumlu etkisi Kanadlı (2016) tarafından yapılan meta analiz çalışmasında belirtilmiştir. Ağca (2006), hipermedya ortamlarda Kolb’un öğrenme stillerine dayalı olarak farklı gezinti yapılarının akademik başarıya etkisini incelemiştir. Ağca'nın yürüttüğü çalışmada, özümseyen öğrenme stiline sahip olan bireyler doğrusal yapıda, yerleştiren öğrenme stiline sahip bireyler doğrusal olmayan yapıda, değiştiren öğrenme stiline sahip bireylerin doğrusal yapıda ve son olarak ayrıștıran öğrenme stiline sahip olan bireylerin ise doğrusal olmayan yapıda daha başarılı olduğu sonucuna ulaşılmıştır.

Aktif öğrenme stiline sahip bireyler, yaparak ve yaşayarak öğrenme yaşantılarını tercih ederler; dans etmekten, müzik dinlemekten, seramik, heykel gibi el işleriyle uğraşmaktan keyif alırlar; yaratıcılık gerektiren sorunlarla uğraşmayı severler, keşfetmekten ve araştırmaktan hoşlanırlar (Gülbahar \& Alper, 2014). Aktif öğrenen öğrencilerin kendi yaşantıları yoluyla öğrenmeyi tercih etmeleri, keşfetmekten ve araştırmaktan hoşlanmaları çevrimiçi ortamdan ayrıldıktan sonra da onları öğrenmeye güdüleyerek öğrenme performanslarını ve akademik başarılarını artırmış olabilir. Magdalena (2015), yürütmüş olduğu çalışmada pratik ve teorik deneyimlere dayalı 
öğrenme biçimini tercih eden, gerçek yaşama dayalı olarak öğrenmelerini geliştiren öğrencilerin akademik başarısının daha yüksek olduğu sonucuna ulaşmıştır. Ayrıca, aktif öğrenme stilinin öğrenmeye yönelik güdü, sınav kaygısı gibi diğer psikolojik değişkenlerle ilişkisinin diğer öğrenme stillerinden farklı olma olasılığı, de aktif öğrenme stiline sahip olan öğrencilerin akademik başarısında diğer e-öğrenme stillerine sahip olan öğrencilere göre farklılık oluşturmuş olabilir. $\mathrm{Bu}$ nedenle başka araştırmalarda e-öğrenme stilleriyle öğrenmeye yönelik güdü, sınav kaygısı, üstbilişsel farkındalık gibi psikolojik değişkenlerin ilişkisi araştırılabilir.

Araştırmada bağımsız öğrenme stili ile akademik başarı arasında düşük ve negatif bir ilişki olduğu, aynı zamanda bağımsız öğrenme stilinin akademik başarının da bir yordayıcısı olduğu belirlenmiştir. Bağımsız öğrenme stiline sahip olan öğrenciler, kendi başına çalışmayı tercih eder; kendi öğrenmelerinin sorumluluğunu alır; öğrenme yeteneği konusunda kendine güvenir; forum, wiki ve blog gibi farklı zamanlı etkinliklerle ilgilenir; bireysel çalışmalardan keyif alırlar (Gülbahar \& Alper, 2014). Alanyazında uzaktan eğitim sürecinde öğrenme ortamının özelliklerinin ve öğretmen rehberliğinin önemine vurgu yapan çok sayıda araştırma bulgusu vardır (Ilgaz \& Aşkar, 2009; Vonderell \& Sarvery, 2004; White, 2005). Bağımsız öğrenme stilinin akademik başarıyla ters yönlü bir ilişki vermesinin nedeni bağımsız öğrenme stiline sahip olan öğrencilerin öğretmen rehberliğine gereksinim duymadıklarını düşünmeleri ve öğretmen rehberliğinden bağımsız çalışmaları olabilir. Konuyla ilgili yapılacak sonraki çalışmalarda bağımsız öğrenme stiline sahip olan öğrencilerin sınıf içi uygulamalarda öğretmenden ne tür bir rehberlik gereksinimi duyduğu ve ders çalışma alışkanlıklarının neler olduğunun belirlenmesi bu araştırmada elde edilen bulguları açıklayabilir.

Regresyon eşitliğine yalnız aktif ve bağımsız öğrenme stillerinin girmiş olmasının nedeni öğretim yönetim sisteminde yalnız video konferans yöntemiyle öğretimin gerçekleştirilmesi de olabilir. E-öğrenme stilleriyle ilgili alanyazında, öğrenme ortamlarının e-öğrenme stillerine göre düzenlenmesi ve öğrencilerin farklı eöğrenme stilleriyle ilgili farkındalık kazandırılmasının önemini belirten açıklamalara yer verilmişti. $\mathrm{Bu}$ çerçevede araştırma bulguları değerlendirildiğinde, uzaktan eğitim yoluyla gerçekleştirilen öğretim yönetim sistemlerinin geleneksel yollardan farklı olarak daha fazla dijital öğrenme firsatları yaratması e-öğrenme stilleriyle etkileşerek öğrenci başarısını artırabilir. Konuyla ilgili çeşitli videolar, tartışma ortamları, performans görevleri, öğrencilerin sürece aktif katılımını sağlayabilecek başka bileşenler kullanıldığında farklı e-öğrenme stillerine sahip olan öğrencilerin akademik başarılarında değişme olabilir.

Sözü edilen bu bilgilerin yanı sıra, alanyazında öğrenme stillerinin akademik başarıyı açıklamada yetersiz kaldığına ve öğrenme stilleri kuramlarının yeterince açık ve net bir kuramsal yap1 oluşturamadığına ilişkin tartışmalar da söz konusudur (Kozhevnikov, 2007). Öğrenme stilleri ve akademik başarı arasında yapılan çalışmalar genellikle geleneksel öğrenme ortamlarında öğrencilerin davranışlarının gözlenmesine dayalı olarak gerçekleştirilmiştir. Çevrimiçi öğrenme ortamlarında ise sohbete katılma, soru sorma, çevrimiçi görevleri zamanında yükleme, çevrimiçi tartışmalara katılma gibi öğrenci davranışlarının dolaylı göstergeleri söz konusudur. Dağ ve Geçer'in (2009) çevrimiçi öğrenme ve e-öğrenme stilleri ile ilgili yapmış olduğu çalışmada, e-öğrenme stillerinin çevrimiçi öğrenme ortamlarında akademik başarının iyileştirilmesine etki eden tek bir faktör olmadığı vurgulanmaktadır. Ayrıca öğrencilerin güdülenmeleri, 
cinsiyet, yaş gibi kişisel özellikleri, e-öğrenme ortamında kullanılan öğretim stratejileri ve öğretim yöntemleri gibi diğer etmenlerin de sonuçları nasıl etkileyebileceğinin araştırılması önerilmektedir.

$\mathrm{Bu}$ araştırmada regresyon eşitliğine giren iki e-öğrenme stili, akademik başarıyı etkileyebilecek ders çalışma alışkanlıkları gibi başka psikolojik değişkenlerle ilişkili olabilir. Farklı e-öğrenme stillerine sahip olan öğrencilerin, ders çalışma yöntemlerinde ve öğrenme süreçlerinde önemli farkl1lıklar söz konusu olabilir (Somuncuoğlu \& Y1ldırım, 1998; Junko, 1998). Farklı e-öğrenme stillerine sahip olan öğrencilerin farklı ders çalışma alışkanlıklarına sahip olması da onların akademik başarılarını etkilemiş olabilir. Şenel ve Kutlu'nun (2015) yürütmüş olduğu araştırmada benzer bir bulguya ulaşılarak öğrencilerin ne kadar süreyle ders çalıştıklarından daha çok nasıl ders çalıştıklarının akademik başarı üzerinde etkili olduğu belirlenmiştir. Çakıroğlu (2014) öğrenme stilleri ile öğrencilerin ders çalışma alışkanlıkları, dikkat, çalışma planlarını oluşturma ve bu plana uyma becerileri arasında önemli ilişkiler olduğunu bulmuştur. $\mathrm{Bu}$ nedenle başka araştırmalarla farklı e-öğrenme stillerine sahip olan öğrencilerin ders çalışma yöntemleri ve akademik başarıları arasındaki ilişkilerin belirlenmesi; bu değişkenlerle öğrenmeye isteklilik, güdülenme gibi diğer psikolojik değişkenlerle ilişkilerin araştırılması alana katkı sağlayabilir.

Örgün eğitimde, etkili öğrenmeyi gerçekleştirebilmek için ders tasarımları ve öğretim stratejileri bulunmaktadır. $\mathrm{Bu}$ süreçte ise öğretim kalitesi öğrenci özelliklerinden, öğretmenin öğretme stillerinden etkilenmektedir (Keefe, 1987). Bu nedenle öğrenme stillerine uygun bir öğretim hizmeti sağlamak, öğrencilerin sadece akademik olarak başarılarının artmasına değil, aynı zamanda farklı olana hoşgörü geliştirmeye, daha disiplinli olmaya, öğretime ilişkin olumlu tutum geliştirmeye katkılar sağlayabilir (Veznedaroğlu \& Özgür, 2005).

Sonuç olarak bu araştırmada çevrimiçi derslere katılım, video kayıtları sonraki bir zamanda izleme, aktif ve bağımsız öğrenme stilleri akademik başarıyı yordadığı bulunmuştur. $\mathrm{Bu}$ dört değişken akademik başarıdaki toplam varyansın \%7'sini açıklamaktadır. Çevrimiçi derslere katılım, video kayıtları sonraki bir zamanda izleme, aktif öğrenme stili ile akademik başarı arasında düşük ve pozitif yönlü bir ilişki, bağımsız öğrenme stili ile akademik başarı arasında düşük ve negatif düzeyde ilişki bulunmuştur. E-öğrenme stilleri ile akademik başarı arasındaki ilişkilerin düşük düzeyde olmasının nedeni öğretim yönetim sisteminin yalnız video konferans biçiminde yürütülmüş olması, çeşitli öğrenme araçlarına yer verilmemiş olması olabilir. Ayrıca öğrencilerin uzaktan eğitim yoluyla öğrenmede etkili olabilecek diğer psikolojik ve bilişsel gerekliliklere (güdülenme, öz düzenleme, zaman yönetimi, yaşam boyu öğrenme eğilimi vb.) sahip olmaması da sonucu etkilemiş olabilir. $\mathrm{Bu}$ nedenle bundan sonra gerçekleştirilecek araştırmalarda farklı ortamlarla düzenlenmiş öğretim yönetim sistemleri kullanılarak yapılacak deneysel çalışmalarda güdülenme, öz düzenleme, zaman yönetimi, yaşam boyu öğrenme eğilimi, e-öğrenme stratejileri gibi çok sayıda değişkene ilişkin ölçümler elde edilerek ortak etkileşimlerinin akademik başarıda nasıl bir değişim yarattığı araştırılabilir. 


\section{Summary}

Purpose and Significance: With the rapid spread of e-learning environments in many institutions, it is important to investigate the learning characteristics of these environments, to design e-learning environments more effectively and to improve learning performance. Buerck, Malstrom, and Peppers (2003) have suggested that learning styles as a variable would be a deficit in studies that attempt to explain student success in e-learning environment, particularly when the impact of learning individual differences is often expressed. Cook (1991) notes that the determination of learning styles is important in bringing learning style awareness, and that the acquisition of learning style awareness contributes positively to academic achievement. It was seen that there is no study on the relationships between the learning styles and academic achievement in e-learning environment have been conducted in Turkey. For this reason, the effect of learning styles of students in e-learning environments on academic achievement was investigated in this study. In the survey, the answer was searched for "e-learning styles, participation in online classes, watching video records are the predictors of academic achievement?"

Method: Correlational survey research design was used in this study. The study group consists of 501 students (351 female and 150 male). These students have taken the measurement and assessment course for 14 weeks in the 2016-2017 academic year through distance learning within the Pedagogical Formation Certificate Program. The course was carried out online with learning management systems. These students were undergraduate and final grades in different departments. The Achievement Test were used as a measure of academic success in the research. In addition, E-Learning Styles Scale and Personal Information Form were used in the research. In the analysis of the data, a stepwise multiple regression analysis was used. Normal distribution, linearity, constant variance, absence of autocorrelation, and lack of multiple links between independent variables were examined from the assumptions of multiple linear regression analysis.

Results: In regression analysis, only active learning and independent learning styles in learning styles in e-learning environments have had a significant impact on academic achievement. When $R^{2}$ values of the predictor variables are examined, they are contributing $2 \%$ to watching video recordings, $1 \%$ participation in online courses, $1 \%$ active learning style and $2 \%$ independent learning style in terms of explaining the total variance in academic achievement. These four variables together account for $7 \%$ of the total variance associated with academic achievement.

Discussion and Conclusions: According to the results of the study, four of the variables included in the analysis contributed to the prediction of academic achievement. Monitoring video recordings, participating in online courses, active learning style and independent learning style predicted the academic achievement in the e-learning environment. Participation in online courses and monitoring of course video recordings at a later time enhances academic success. This shows the importance of the role of the teacher during the learning experiences of the students. It has been determined that there 
is a positive and low level of relationship between the status of having active learning style and academic achievement and it is a predictor of academic achievement. Students with active learning style prefer learning by doing and living; enjoying dancing, listening to music, handcrafting ceramics, sculpture, etc. ; they like to deal with the problems that require creativity, they like to explore and research (Gülbahar \& Alper, 2014). These preferences may have increased academic achievement by increasing learning performance. Another findings, it has been determined that there is a low and negative relationship between the independent learning style and academic achievement in the research and it is a predictor of academic achievement. Students with independent learning style prefer to work on their own; take the responsibility of their own learning; confidence in learning ability; deals with different time events such as forums, wikis and blogs; enjoy their individual work (Gülbahar \& Alper, 2014). The fact that the independent learning style has an adverse relationship with the academic achievement may be due to the students with independent learning style do not need teacher guidance and may work independently from the teacher guidance. As a result, participation in online lectures, video recordings at a later time, active and independent learning styles found academic success in this research. These four variables account for $7 \%$ of the total variance in academic achievement. In formal education, there are course designs and instructional strategies to make effective learning possible. In this process, the teaching quality is influenced by the student characteristics, the teacher's teaching style (Keefe, 1987). For this reason, providing a teaching service suited to learning styles can provide a contribution not only to the academic achievement of the students but also to the development of tolerance, discipline and positive attitude towards teaching (Veznedaroğlu \& Özgür, 2005). 


\section{Kaynakça}

Ağca, R., K. (2006). Hipermedya ortamlarda öğrenme stillerine dayalı farklı Gezinti yapılarının öğrenci başarısına etkisi (Yayımlanmamış Yüksek Lisans Tezi). Gazi Üniversitesi Eğitim Bilimleri Enstitüsü, Ankara.

Albayrak, A. S. (2006). Uygulamalı çok değişkenli istatistik teknikleri. Asil Yayın Dağıtım.

Badge, J. L., Saunders, N. F., \& Cann, A. J. (2012). Beyond marks: new tools to visualise student engagement via social networks. Research in Learning Technology, 20(1), 1-14.

Beadles II, N. A., \& Lowery, C. M. (2007). Self-selection into degree programs: Differences in preferred learning styles between online students and traditional students. Academy of Educational Leadership Journal, 11(2), 103-112.

Buerck, J. P., Malmstrom, T., \& Peppers, E. (2003). Learning environments and learning styles: Non-traditional stdent enrollment and success in an Internet-based versus a lecture-based computer science course. Learning Environments Research, 6(2), 137-155.

Butler, K. A. (1987). Learning and teaching style: In theory and practice. Learners Dimension, Colombia.

Büyüköztürk, Ş. (2017). Sosyal bilimler için veri analizi el kitabı. (23. Baskı) Pegem Atıf İndeksi, 1-213.

Büyüköztürk, Ş., Çakmak, E. K., Akgün, Ö. E., Karadeniz, Ş., \& Demirel, F. (2017). Bilimsel araştırma yöntemleri. (23. Baskı). Pegem Atıf İndeksi, 1-360.

Canfield, A. A. (1988). Learning styles inventory. Los Angeles, CA: Western psychological services.

Cassidy, J. (2004). Learning styles: An overview of theories, models, and measures. Educational Psychology, 24(4), 419-444.

Chen, C. J. (2019). Differences between visual style and verbal style learners in learning English. In Information Resources Management Association, Computer-Assisted Language Learning: Concepts, Methodologies, Tools, and Applications (18941908), IGI Global.

Cook, L. (1991). Learning style awareness and academic achievement among community college students. Community College Journal of Research and Practice, 15, 419-425.

Çakıroğlu, Ü. (2014). Analyzing the effect of learning styles and study habits of distance learners on learning performances: A case of an introductory programming course. The International Review of Research in Open and Distributed Learning, 15(4), 161-184.

Dağ, F., \& Geçer, A. (2009). Relations between online learning and learning styles. Procedia Social and Behavioral Sciences, 1(1), 862-871.

Felder, R.M. (1993). Reaching the second tire-learning styles and teaching styles in college science education. Journal of College Science Teaching, 23(5), 286-290. 
Felder, R. M. (1996). Matters of styles. ASEE Prism, 6(4), 18-23. http://www.ncsu.edu/felderpublic/Papers/LS-Prism.htm adresinden 22.02.2018 tarihinde erişilmiştir.

Felder, R. M., \& Siverman L. (1988). Learning and teaching styles in engineering education. Engineering Education, 78(7), 674-681. http://www.ncsu.edu/felderpublic/Papers/LS-1988.pdf. adresinden 22.02.2018 tarihinde erişilmiştir.

Geiser, W. F., Dunn, R., Deckinger, E. L., Denig, S., Sklar, R. I., Beasley, M., \& Nelson, B. (2000). Effects of learning-style awareness and responsive study strategies on achievement, incidence of study, and attitudes of suburban eighthgrade students. National Forum of Applied Educational Research, 13(2), 37-49.

Gülbahar, Y., \& Alper, A. (2014). Development of e-learning styles scale for electronic environments. Education and Science, 39(171), 421-435.

Gregorc, A. F. (1979). Learning/teaching styles: Their nature and effects. In National Association of Secondary School Principals (Ed.), Student learning styles: Diagnosing and prescribing programs (pp. 19-26). Reston: National Association of Secondary School Principals.

Howland, J. L., \& Moore, J. L. (2002). Student perceptions as distance learners in Internet-based courses. Distance Education, 23(2), 83-195.

Hsu, T. E. (1994). Effects of learner cognitive styles and metacognitive tools on information acquisition paths and learning in hyperspace environments. 16. National Convention of the Association for Educational communications and Technology Kongresi. Nashville, TN, February 16-20. https://eric.ed.gov/?id=ED373721 adresinden 9.1.2018 tarihinde erişilmiştir.

Ilgaz, H., \& Aşkar, P. (2009). Çevrimiçi uzaktan eğitim ortamında topluluk hissi ölçeği geliştirme çalışması. Turkish Journal of Computer and Mathematics Education, 1(1), 27-35.

Jahanbakhsh, R. (2012). Learning styles and academic achievement: A case study of Iranian high school girls' students. Procedia- Social and Behavioral Sciences, 51, $1030-1034$.

Junko, U. (1998). Learning styles and error correction: How do learning styles affect students' perceptions towards error correction in a foreign language classroom? https://eric.ed.gov/?id=ED429452 adresinden 23.01.2018 tarihinde erişilmiştir.

Kalaycı, Ş. (2009). SPSS uygulamalı çok değişkenli istatistik teknikleri. Ankara: Asil Publishing.

Kanadl1, S. (2016). A meta-analysis on the effect of instructional designs based on the learning styles models on academic achievement, attitude and retention. Educational Sciences: Theory \& Practice, 16, 2057-2086.

Keefe, J. W. (1987). Learning style theory and practice. Reston VA: National Association of Secondary School Principals.

Kia, M. M., Aliapour, A., \& Ghaderi, E. (2009). Note for editor: Study of learning styles and their roles in the academic achievement of the students of Payame Noor University (PNU). Turkish Online Journal of Distance Education, 10(2), 24-37.

Kolb, D. A. (1981). Learning styles and disciplinary differences. The Modern American College, 1, 232-255. 
Kozhevnikov, M. (2007). Cognitive styles in the context of modern psychology: Toward an integrated framework of cognitive style. Psychological Bulletin, 133(3), 464- 481.

Li, R., Yin, C., Zhang, X., \& David, B. (2019). Online learning style modeling for course recommendation. In P. Srikanta \& J. Vipul (Eds.), Recent developments in intelligent computing, communication and devices (pp. 1035-1042). Springer, Singapore.

Magdalena, S. M. (2015). The relationship of learning styles, learning behaviour and learning outcomes at the romanian students. Procedia-Social and Behavioral Sciences, 180, 1667-1672.

Maki, R. H., \& Maki, W. S. (2007). Online courses. In R. S. Nickerson, S. T. Dumais, S. Lewandowsky, \& T. J. Perfect (Eds.), Handbook of applied cognition (pp. 527552), Newyork: John Wiley \& Sons.

McCarthy, B. (1987). The 4MAT system: Teaching to learning styles with right/left mode techniques. Barrington, IL: Excel

Nitko, A. J. (1996). Educational assessment of students. Prentice-Hall Order Processing Center, PO Box 11071, Des Moines, IA 50336-1071.

Omar, N., Mohamad, M. M., \& Paimin, A. N. (2015). Dimension of learning styles and students' academic achievement. Procedia-Social and Behavioral Sciences, 204, 172-182.

Özçelik, D. A. (2010). Ölçme ve değerlendirme. Pegem Akademi.

Pashler, H., McDaniel, M., Rohrer, D., \& Bjork, R. (2008). Learning styles: Concepts and evidence. Psychological science in the public interest, 9(3), 105-119.

Rita, D., \& Dunn, K. (1993). Learning styles/teaching styles: Should they can they... be matched. Educational Leadership, 36(4), 238-244.

Ross, J. L., Drysdale, M. T., \& Schulz, R. A. (2001). Cognitive learning styles and academic performance in two postsecondary computer application courses. Journal of Research on Computing in Education, 33(4), 400-412.

Rovai, A. P. \& Grooms, L. D. (2004). The relationship of personality-based learning style preferences and learning among online graduate students. Journal of Computer in Higher Education, 16(1), 30-47.

Savaş, S., \& Arıcı, N. (2009). Web tabanlı uzaktan eğitimde iki farklı öğretim modelinin öğrenci başarısı üzerindeki etkilerinin incelenmesi. 5. Uluslararası İleri Teknolojiler Sempozyumu (IATS’09), 13-15 Mayıs 2009, Karabük Üniversitesi.

Silver, H. F., Hanson, J. R., \& Strong, R. W. (1979). TLC and cultural learning preference. Applied Research, 11(1), 45-49.

Somuncuoğlu, Y., \& Yıldırım, A. (1998). Öğrenme stratejileri: Teorik boyutları, araştırma bulguları ve uygulama için ortaya koyduğu sonuçlar. Eğitim ve Bilim, 22(110), 31-39.

Şenel, S., \& Kutlu, Ö. (2015). Ankara üniversitesi uzaktan eğitim programına katılan öğrencilerin akademik başarılarını yordayan faktörler. Eğitimde ve Psikolojide Ölçme ve Değerlendirme Dergisi, 6(2), 177-193. 
Tulbure, C. (2011). Learning styles, teaching strategies and academic achievement in higher education: A cross-sectional investigation. Procedia Social and Behavioral Sciences, 33, 398-402.

Turgut, M. F., \& Baykul, Y. (2012). Eğitimde ölçme ve değerlendirme. Pegem Akademi.

Veznedaroğlu, R., L., \& Özgür, A., O. (2005). Öğrenme stilleri: Tanımlamalar, modeller ve işlevleri. İlkögretim Online, 4(2), 1-16.

White, C. (2005). Contribution of distance education to the development of individual learners. Distance Education, 26(2), 165-181.

Willingham, D. T., Hughes, E. M., \& Dobolyi, D. G. (2015). The scientific status of learning styles theories. Teaching of Psychology, 42(3), 266-271.

Witkin, H.A. (1964). Origins of cognitive style. In C. Sheerer (Ed.), Cognition, theory, research, promise. New York: Harper and Row.

Yavuzalp, N., \& Gürol, M. (2017). E-öğrenme ortamında kullanılan öğrenme stillerinin web kullanım madenciliği ile analizi. Abant İzzet Baysal Üniversitesi Ĕ̈itim Fakültesi Dergisi, 17(2), 987-1015.

Yurdakul, B. (2016). Yapılandırmacılık. In Özcan Demirel (Ed.), Eğitimde yeni yönelimler (pp. 39-65). Pegem Atıf İndeksi.

This is an Open Access article distributed under the terms of the Creative CommonsAttributionNonCommercial-ShareAlike 4.0 International (CC BY-NC-SA 4.0). For further information, you can refer to https://creativecommons.org/licenses/by-nc-sa/4.0/ 